SHCC4: 4th International Conference on Strain-Hardening Cement-Based Composites (SHCC 4) 18-20 September 2017, Dresden, Germany.

\title{
Experimental study of tensile response of Strain Hardening UHPFRC at early age
}

\author{
Mohamed A. Hafiz ${ }^{1}$ and Emmanuel Denarié ${ }^{1}$
}

${ }^{1}$ Division of Maintenance and Safety of Structures (MCS-IIC-ENAC), Ecole Polytechnique Fédérale de Lausanne (EPFL), GC B3-445, Station 18, CH-1015 Lausanne, Switzerland, fax. +41-21-693 58 85, email: mohamed.hafiz@epfl.ch

\begin{abstract}
Strain Hardening Ultra High Performance Fibre Reinforced Concrete (SH-UHPFRC), has a high tensile strength (over $10 \mathrm{MPa}$ ) and exhibit significant strain hardening (several \%o) under tensile loads. These appealing features make it a suitable material for improving the efficiency and durability of new or existing structures. However, in rehabilitation works, when a layer of a new material is applied on an existing structure, due to restraints from the existing structure, the shrinkage deformations lead to high tensile stresses in the new layer, which can lead to premature cracking.

To characterize the effect of the restraining conditions, experimental investigations of evolution of autogenous shrinkage and development of eigenstresses were done using a Temperature Stress Testing Machine (TSTM) at quasi-isothermal curing conditions at $20^{\circ} \mathrm{C}$, from the time of casting. Tests were done at partial and full restraint conditions to study the development of the eigenstresses. The tests with 100\% restraint are the first of their kind on SH-UHPFRC and the results show that under full restraint conditions, the material enters into the strain-hardening zone of the tensile response.
\end{abstract}

Keywords: UHPFRC, Tensile response, TSTM, Strain Hardening, Early age.

\section{INTRODUCTION}

Ultra High Performance Fibre Reinforced Concrete (UHPFRC) are materials with very low permeability, outstanding durability and excellent mechanical properties including high tensile strength (over $10 \mathrm{MPa}$ ). With a suitable fibrous mix, they can exhibit significant strain hardening response in tension (1-5\%o). As such, they are very well adapted for strengthening and protective functions of existing structures. 
One of the main applications of UHPFRC is in the strengthening of existing structures wherein a new layer of UHPFRC is applied on an old layer of concrete. Such conditions lead to the development of tensile stresses in the new layer due to restrained shrinkage. The new layer of UHPFRC undergoes early age volume changes due to thermal effects and autogenous shrinkage. These deformations are restrained by the existing support conditions and reinforcement bars in the new layer if any, which lead to tensile eigenstresses.

These eigenstresses are often not given enough consideration, but the present study shows that they can be very high depending on the restraint conditions. Denarié (2006) showed that depending on the stiffness of the existing structure, the degree of restraint can be as high as $90 \%$. However, in most cases, the strain hardening capacity of SH-UHPFRC helps to mitigate the detrimental effects of these high eigenstresses, except in very special cases of unfavourable fibre orientations. Moreover, the viscoelastic potential in tension of UHPFRC also plays a favourable role in relaxing the early age eigenstresses.

The situation becomes even worser, when the onsite casting of UHPFRC is carried out at low temperatures. Since at low temperatures, the hydration progresses at a lower rate, the chances of the eigenstresses exceeding the strength of the material at the early age, are even higher. As such, it is important to study about the development of these eigenstresses in the early age due to restrained shrinkage to optimize the use of UHPFRC in cast-on site applications.

Not much attention has been given to the study of development of eigenstresses in UHPFRC in the early age just after setting. Especially, no work has been done until now to study the eigenstresses development under $100 \%$ restraint (full restraint) conditions.

To investigate the early age behavior of UHPFRC, a Temperature Stress Testing Machine (TSTM) was used which was developed at MCS during the thesis of Kamen (2008). The system was developed based on previous works done by Charron (2004). Kovler, Igarashi, and Bentur (1999) investigated the tensile creep of high strength concrete under restrained conditions using an incremental procedure using TSTM. Kamen, Denarié, Sadouki, and Brühwiler (2008) followed a similar incremental procedure and conducted restrained shrinkage tests on UHPFRC specimens. In addition, the development of Elastic modulus of UHPFRC was also studied using a Vibration Resonance Frequency (VRF) test setup, following the procedures developed by Kazemi Kamyab (2013).

\section{MATERIAL}

SH-UHPFRC type CM22-TKKb, from the CEMTEC multiscale $^{\circledR}$ family, was used for this study. Because of the low water/binder ratio, and optimized packing, it has a very compact cementitious matrix. The compact matrix along with the fibres, makes the mix very low in permeability, high in strength and also gives it the property of strain hardening behavior in tension. Table 1 shows the composition of the mix used in the study. 


\section{Table 1. UHPFRC recipe}

\begin{tabular}{lc}
\multicolumn{1}{c}{ Material } & {$\left[\mathrm{kg} / \mathrm{m}^{3}\right]$} \\
\hline Cement/silica fume & $1467.0 / 381.4$ \\
${ }^{*}$ Steel fibres (straight macro fibres, slightly & 706.5 \\
torqued: $\mathrm{l}_{\mathrm{f}}=10 \mathrm{~mm}, \mathrm{~d}_{\mathrm{f}}=0.2 \mathrm{~mm}$ and & \\
microfibers/steel wool) & $225.8 / 20.5$ \\
\hline Water/superplasticizer & \\
\hline *: detailed fibrous mix is patent protected &
\end{tabular}

\section{EXPERIMENTS}

\subsection{Vibration Resonance Frequency Test (VRFT)}

Vibration Resonance Frequency tests were done to study the development of Elastic modulus of UHPFRC. The tests were conducted in order to collect data required for modelling the tensile response of the material under various restraint conditions. The tests were carried out in a climate chamber maintained at a temperature of $20^{\circ} \mathrm{C}$ on specimens that were cured at $20^{\circ} \mathrm{C}$. Cylinders of dimensions $14 \mathrm{~cm} / 7 \mathrm{~cm}$ were used for the tests. The procedure for the determination of development of Elastic modulus was developed by Kolluru, Popovics, and Shah (2000). The cylindrical specimens, after setting, were hit with a steel sphere at the centre, which produced longitudinal vibrations in the specimen. The resulting vibrations were measured using an accelerometer and the longitudinal resonance frequencies were measured. With a help of an analytical procedure, the elastic modulus and Poisson ratio of the specimen were then determined from the first two longitudinal resonant frequencies of the specimen.

\subsection{Temperature Stress Testing Machine (TSTM)}

The TSTM setup developed at MCS during the doctoral thesis of Kamen (2008) is a thermomechanical test setup, which helps in conducting tests on the UHPFRC specimens at very early age directly after casting at different temperature conditions. It consists of two devices; the first one known as the Free Setup (FS) helps to measure the free autogenous deformation whereas the second device known as the Restrained Setup (RS) helps in measuring the eigenstresses developing under various restraint conditions, as well as the associated free deformations. In both the devices fully sealed specimens of cross sectional dimensions $50 \mathrm{~mm}$ x $100 \mathrm{~mm}$ were used. The two setups are shown in figure 1 .

Two types of tests were conducted on the fresh UHPFRC specimens: full restraint tests and partial restraint tests. Both the set of tests were carried out at a temperature of $20^{\circ} \mathrm{C}$ in the RS setup. For the full restraint tests, the tests were started under stroke control (passive restraint, stroke idle) until the setting of the fresh material. After setting, when the stress in the material reached about $0.2 \mathrm{MPa}$, the control was switched to strain control. Under strain control, the strains were controlled in such a way that the relative displacement between two points $A$ and B about $750 \mathrm{~mm}$ apart, remained constant. The control was therefore an active control as the 
displacements were controlled actively depending on the shrinkage occurring in the material. This ensured full restraint conditions in the material thereby leading to higher eigenstresses.

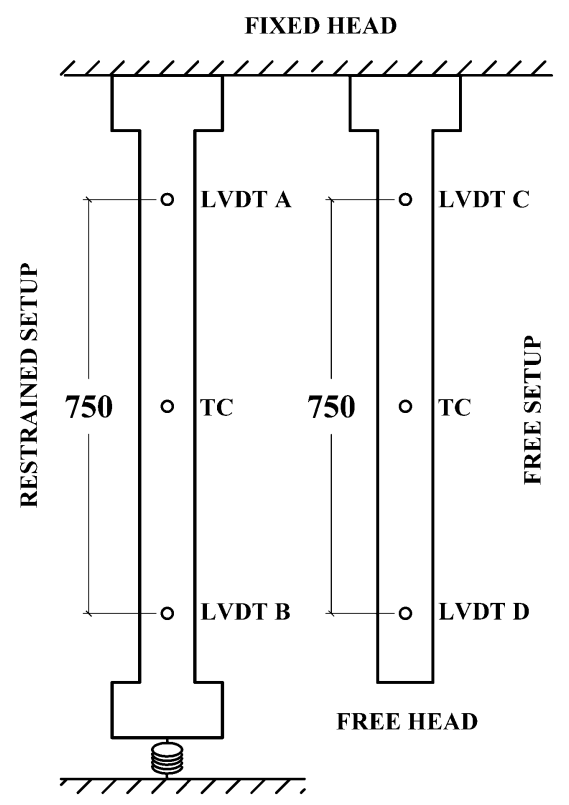

Figure 1. Schematic representation of TSTM testing setup with TC: Thermocouple, LVDT: displacement transducer (all measurements are in millimetres)

In the partial restraint tests, the entire test was controlled though stroke control and the stroke was kept in the same relative position without any movement. Even though it may seem like a full restraint test, it is not a $100 \%$ restraint test because of the finite stiffness of the machine parts. Due to the finite stiffness, there was always a very slight displacement of the machine parts which made the test not fully restrained. If the machine had infinite stiffness, then this stroke controlled test would also have been a fully restraint test. The partial restraint imposed by the machine in a stroke-controlled test was calculated to be approximately $50 \%$.

Depending on the restraint conditions, the autogenous shrinkage led to the development of various magnitudes of eigenstresses within the specimens. In parallel to the restrained tests, the free autogenous deformations were measured in the FS setup for each of the tests, and it was assumed that the restrained specimen exhibited similar autogenous shrinkage as that in the free specimens.

\section{RESULTS AND DISCUSSION}

\subsection{VRFT}

The elastic modulus development of two UHPFRC samples are shown in figure 2. Even though the setting time is slightly different in both the specimens, we can see that the 
development of Elastic modulus follows more or less similar trend. And it can also be seen that the values of the elastic modulus at an age of 7 days are almost similar, being slightly lesser than $51 \mathrm{GPa}$.

The difference in the setting times may be due to the experimental differences between the two batches. The difference could also be due to a change in the components in the meantime between the two batches, as the second sample was made from a new delivery of cement and silica fume.

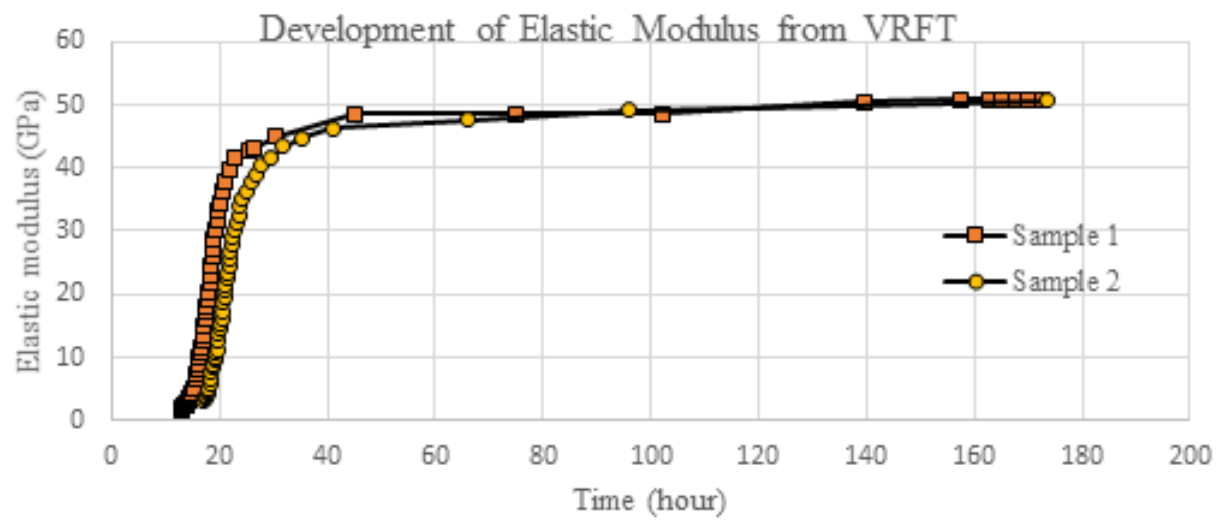

Figure 2. Development of Elastic Modulus from VRFT

\subsection{Autogenous shrinkage at $20^{\circ} \mathrm{C}$ from TSTM}

The autogenous deformation of the UHPFRC was measured using the FS setup of the TSTM. Displacements were measured at two points that were at a distance of $750 \mathrm{~mm}$ from each other. Assuming a uniform evolution of deformations from one end to the other, the autogenous shrinkage between the two points were calculated by subtraction. Figure 3 shows the development of autogenous shrinkage in the two full restraint (FR) tests and one partial restraint $(\mathrm{PR})$ test.

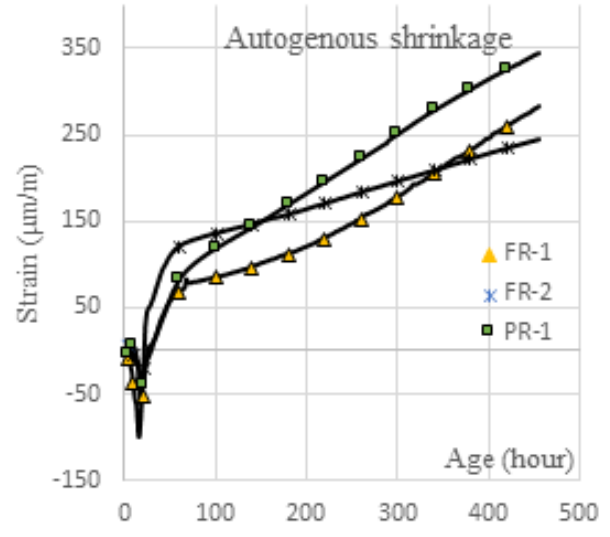

(a)

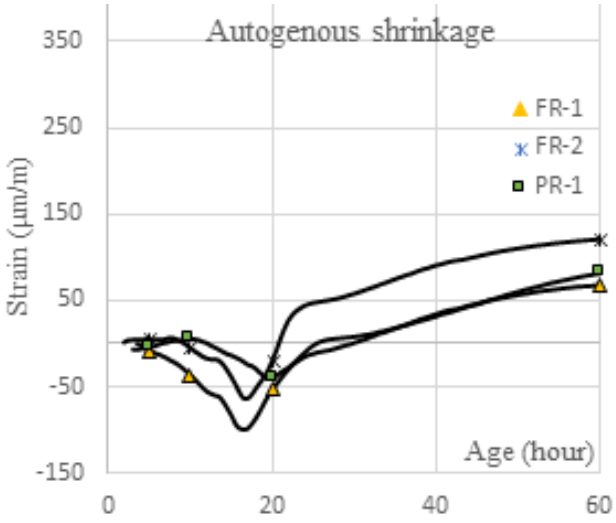

(b)

Figure 3. Evolution of autogenous deformations (shrinkage is shown as positive), (a) overall trend, (b) early age behaviour 
It can be seen that in all the three curves, there is a swelling phase in the evolution of shrinkage followed by an increasing curve. The swelling phase corresponds well with the increase in the temperature within the material during setting. But it is the autogenous shrinkage after the end of the swelling phase that contributes to the development of eigenstresses in the material.

The autogenous shrinkage varies between $108 \mu \mathrm{m} / \mathrm{m}$ and $162 \mu \mathrm{m} / \mathrm{m}$ at 7 days and between $244 \mu \mathrm{m} / \mathrm{m}$ and $343 \mu \mathrm{m} / \mathrm{m}$ at 450 hours. This scatter is comparable to that found in similar UHPFRC mixes by previous authors. Kamen (2008) found an autogenous shrinkage, which varied between $105 \mu \mathrm{m} / \mathrm{m}$ and $140 \mu \mathrm{m} / \mathrm{m}$ at 7 days at $20^{\circ} \mathrm{C}$. Switek-Rey, Denarié, and Brühwiler (2016) conducted early age shrinkage tests on similar UHPFRC mix and obtained an autogenous shrinkage of $168 \mu \mathrm{m} / \mathrm{m}$ at 7 days age.

It can be seen from the figure 3 that there is a scatter between the different shrinkage curves. The scatter could be due to the difference in the heterogeneity of the mixes and the differences in the individual mixing procedures or due to non-uniform displacement fileds in the specimen. The free shrinkage was calculated from the displacements measured only at two points that are $750 \mathrm{~mm}$ apart. The scatter could be due to the error in the assumption that the shrinkage varies linearly from one end to the other. More tests, especially with optical measurements, need to be conducted to confirm the assumption of linear variation of the autogenous shrinkage. However, since the scatter is within the ranges found in the previous studies, we can assume that the values are acceptable.

\subsection{Eigenstresses development at $20^{\circ} \mathrm{C}$}

In parallel to the measurement of the evolution of free shrinkage, the development of eigenstresses in the material was also studied. Two tests under full restraint conditions and one test under partial restraint were performed. All the tests were carried out under quasiisothermal temperature conditions at $20^{\circ} \mathrm{C}$, imposed by a cooling circuit.

\subsubsection{Stress development under partial restraint conditions}

The partial restraint tests were carried out under stroke control. Even though the stroke was kept at the same relative position from the start of the test, because of the finite stiffness of the machine parts, a full restraint could not be attained and the material is therefore under partial restraint conditions. The development of eigenstresses under this conditions is shown in figure 5. It can be clearly seen from the graph that the stresses are much lesser than in the case of the full restraint conditions.

\subsubsection{Stress development under full restraint conditions}

As mentioned earlier, the full restraint conditions were ensured by keeping the strains between two points A and B that are $750 \mathrm{~mm}$ apart, constant, under strain control. The displacements measured by the LVDTs A and B for both the full restraint tests, as shown in figure 4, are respective mirror images of each other which confirms zero relative displacement between the points. 


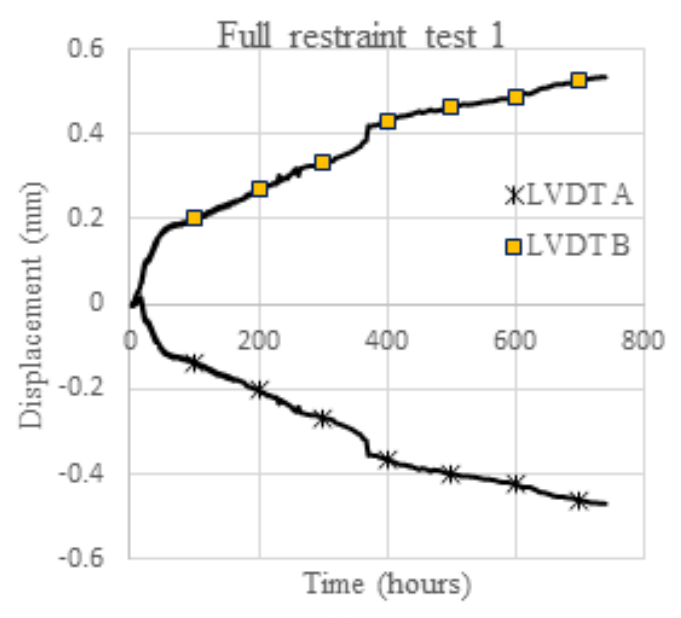

(a)

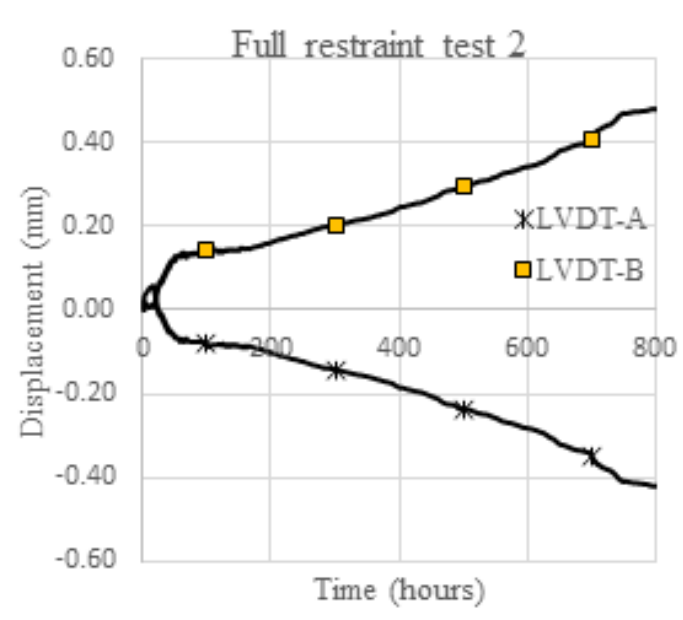

(b)

Figure 4. Comparison of LVDTs A\&B in the full restraint tests (a) Test 1, (b) Test 2

Even though both the points $\mathrm{A}$ and $\mathrm{B}$ were seen moving in one direction, the relative displacements between the two were kept zero, thereby ensuring full restraint conditions. The development of the eigenstresses under these conditions are shown in figure 5.

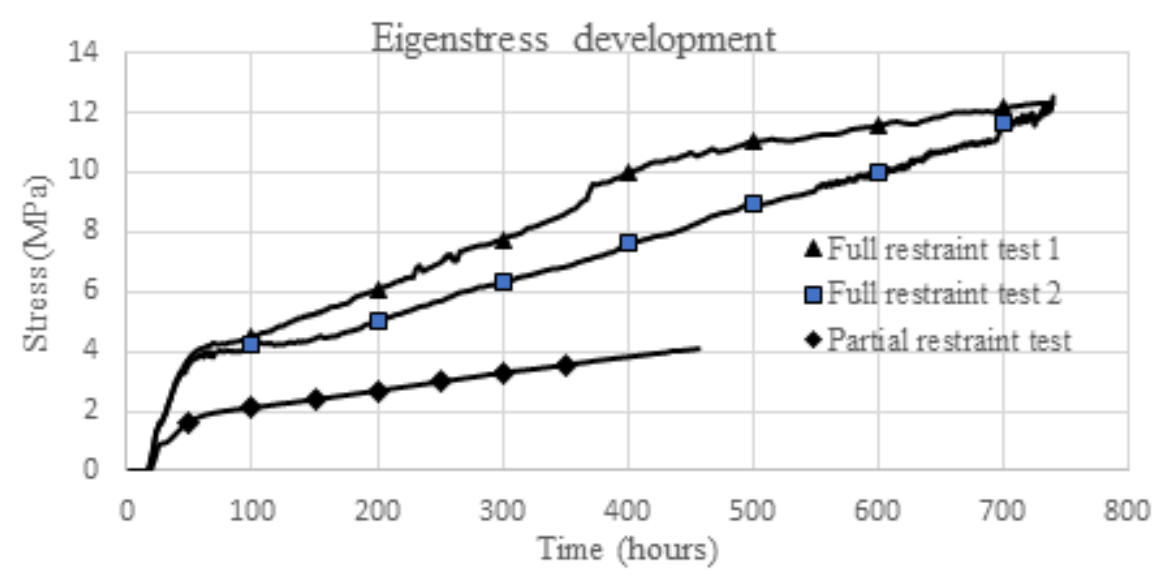

Figure 5. Development of eigenstresses under different restraint conditions

It can be seen from the figure 5, that in full restraint tests, the stresses developed are very high and even more than $12 \mathrm{MPa}$ after around one month. From tensile tests on dumbbell specimens of cross section $30 \mathrm{~mm} \times 50 \mathrm{~mm}$ made from the same material, it was seen that the elastic limit was approximately between $7 \mathrm{MPa}$ and $9 \mathrm{MPa}$. As such, it is reasonable to assume that the material has reached the strain-hardening zone of the tensile response.

The full restraint tests therefore show that the stresses can be much more than the elastic limit of the material. Moreover, it could reasonably be assumed that the eigenstresses will continue to increase along the stress-deformation path of the strain hardening response of the material, as long as the autogenous shrinkage increases. It was seen from some of the tests done at MCS-EPFL that the autogenous shrinkage keeps on increasing even after one year after 
casting. As such, there is a chance that the eigenstresses also keep on increasing and could even be much more than what is shown in these experimental results.

It is therefore very important to have a strain hardening material such as UHPFRC in overlaying applications, to meet the serviceability criterion of protection of the structure, without crack localization.

\section{CONCLUSION}

From the experimental investigations in the study, it is very clear that the influence of autogenous shrinkage and the development of eigenstresses in protective overlays over existing structures, are factors that should be given serious consideration. The tests show that depending on the restraint conditions, the stresses can be even higher than the elastic limit of the material, thereby necessitating the use of a strain hardening material like UHPFRC for such applications, in order to meet the serviceability criterion. More tests are required at high restraint conditions at various temperatures to clearly define the properties required for the materials to be used in such applications in order to optimize their use.

\section{ACKNOWLEDGEMENT}

The project was financially supported by the Swiss National Science Foundation (grant 200021_153394/1). The authors would like to appreciate the help given by the technicians of GIC-ENAC-EPFL in performing the experimental works with the TSTM.

\section{REFERENCES}

Charron, Jean-Philippe. (2004). Contribution à l'étude du comportement au jeune âge des matériaux cimentaires en conditions de déformations libre et restreinte. Ph. D. thesis, CRIB, Univeristé Laval, Québec.

Denarié, Emmanuel. (2006). Deliverable D25b "Guidance for the use of UHPFRC for rehabilitation of concrete highway structures" SAMARIS Project, SAM_GE_DE25v04_01, WP 14: HPFRCC (High Performance Fibre Reinforced Cementitious Composites) for rehabilitation.

Kamen, Aicha, Denarié, Emmanuel, Sadouki, Hamid, \& Brühwiler, Eugen. (2008). Thermomechanical response of UHPFRC at early age - Experimental study and numerical simulation. Cement and Concrete Research, 38(6), 822-831.

Kazemi Kamyab, Mohammadhadi. (2013). Autogenous Shrinkage and Hydration Kinetics of SHUHPFRC under Moderate to Low Temperature Curing Conditions. Doctoral thesis, $\mathrm{N}^{\circ} 5681$, Ecole Polytechnique Fédérale de Lausanne, Switzerland.

Kolluru, Subramaniam V, Popovics, John S, \& Shah, Surendra P. (2000). Determining elastic properties of concrete using vibrational resonance frequencies of standard test cylinders. Cement, concrete and aggregates, 22(2), 81-89.

Kovler, K, Igarashi, S, \& Bentur, A. (1999). Tensile creep behavior of high strength concretes at early ages. Matérials and structures, 32(5), 383-387.

Switek-Rey, Agnieszka, Denarié, Emmanuel, \& Brühwiler, Eugen. (2016). Early age creep and relaxation of UHPFRC under low to high tensile stresses. Cement and Concrete Research, 83, 57-69. 